\title{
SENTIMENTOS DA PUÉRPERA PRIMÍPARA NOS CUIDADOS COM O RECÉM- NASCIDO*
}

Marina Cortez Pereira', Estefânia Santos Gonçalves Félix Garcia², Maria Betânia Tinti de Andrade², Clícia Valim Côrtes Gradim ${ }^{4}$

\begin{abstract}
RESUMO: Este estudo objetivou desvelar os sentimentos da primípara frente ao cuidado com o recém-nascido utilizando-se a metodologia qualitativa segundo a Trajetória Fenomenológica. Foram entrevistadas 11 primíparas da cidade de AlfenasMinas Gerais empregando-se a seguinte questão: O que é para você cuidar do seu recém-nascido? A convergência das unidades de significado originou três categorias: Sentimentos ao cuidar do recém-nascido; Cuidado físico com o recémnascido; Sentimentos da mulher em relação ao companheiro frente ao cuidado com o recém-nascido. As primíparas denotam uma gama de sentimentos positivos sobre a experiência de cuidar do seu filho e os discursos revelam que, mesmo diante do medo e da insegurança se sentem capazes de desenvolver funções maternas frente ao cuidar.

PALAVRAS-CHAVE: Período pós-parto; Recém-nascido; Emoções; Enfermagem.

\section{THE FEELINGS OF PRIMIPARAS WHO HAVE RECENTLY GIVEN BIRTH IN CARING FOR THE NEWBORN BABY}

ABSTRACT: This study aimed to reveal the feelings of women who have given birth to their first child regarding the care given to the new-born, using the qualitative methodology, according to the Phenomenological Trajectory. Eleven first-time mothers from the city of Alfenas in the state of Minas Gerais were interviewed, using the following question: To you, what is caring for your new-born? The convergence of the units of meaning gave rise to three categories: Feelings in caring for the newborn; Physical care for the new-born; The woman's feelings in relation to her partner regarding caring for the new-born. The mothers note a range of positive feelings about the experience of caring for their child and the discourses show that, even in the face of the fear and insecurity, the mothers feel able to carry out the maternal functions regarding caring.

KEYWORDS: Post-partum period; Newborn; Emotions; Nursing.

\section{SENTIMIENTOS DE LA PUÉRPERA PRIMÍPARA EN LOS CUIDADOS CON EL RECIEN NACIDO}

RESUMEN: Este estudio tuvo objetivo de desvelar los sentimientos de la primípara delante del cuidado con el recién nacido utilizándose la metodología cualitativa según la Trayectoria Fenomenológica. Fueron entrevistadas 11 primíparas de la ciudad de Alfenas, Minas Gerais, utilizándose la siguiente cuestión: ¿Qué es para usted cuidar de su recién nacido? La convergencia de las unidades de significado ha originado tres categorías: Sentimientos al cuidar del recién nacido; Cuidado físico con el recién nacido; Sentimientos de la mujer acerca de su pareja delante del cuidado con el recién nacido. Las primíparas denotan una gama de sentimientos positivos sobre la experiencia de cuidar de su hijo y los discursos revelan que, mismo delante del miedo y de la inseguridad, se sienten capaces de desarrollar funciones maternas delante del cuidar. PALABRAS CLAVES: Periodo posparto; Recién nacido; Emociones; Enfermería.

*Artigo extraído do Trabalho de Conclusão de Curso em Enfermagem apresentado à Universidade Federal de Alfenas - UNIFAL, 2011.

${ }^{1}$ Enfermeira Residente pelo Programa de Residência Multiprofissional em Saúde da Família da UNIFAL.

${ }^{2}$ Enfermeira. Mestranda pelo Programa de Pós-Graduação em Enfermagem da UNIFAL.

${ }^{3}$ Enfermeira. Mestre em Enfermagem. Professora da Escola de Enfermagem da UNIFAL.

${ }^{4}$ Enfermeira. Doutora em Enfermagem. Professora da Escola de Enfermagem da NIFAL. 


\section{INTRODUÇÃO}

O puerpério, também denominado de sobre parto ou pós parto, é o período que vai da dequitação até a volta do organismo materno às condições pré gravídicas normais, sua duração varia entre 6 a 8 semanas. Durante esse período ocorre um processo gradativo de involução das modificações gerais e locais do organismo materno determinadas pela gestação $0^{(1-2)}$.

O processo de modificações da mulher neste período transpõe o físico, dando enfoque a perspectiva psicanalista que compeende o puerpério como um período de delimitação entre o devaneio, a fantasia inconsciente e a realidade. Além disso, sentimentos como ansiedade e insegurança são comuns na mulher durante os cuidados com o recém-nascido. Isto se relaciona às expectativas do parto, da criança e da reação ambiental; a nova situação exige da mulher um lento e gradual processo de incorporação à nova condição. Para criar e compreender o bebê, a mãe se vê forçada a rever o seu papel de mulher, incorporando uma nova identificação, o de ser mãe e cuidadora, o que pode gerar conflitos internos para desempenhar o novo papel dentro da família e da sociedade ${ }^{(3)}$.

É relevante a maneira como a mulher, no puerpério, enfrenta as diversas modificações emocionais e físicas para ajustar-se ao novo membro da família, aos desconfortos do pós parto, as alterações em sua imagem corporal e à realidade da mudança em sua $v$ ida $^{(4)}$. Mesmo sendo uma época de extrema alegria, para a maioria delas, algumas podem enfrentar situações que não esperavam. Apesar de o parto ligar-se à sentimentos de felicidade e gratidão pelo nascimento de uma criança saudável, algumas mulheres podem sentir-se entristecidas, sobrecarregadas, inseguras e expressarem sentimentos de uma auto imagem prejudicada. Elas podem temer a perda do controle; podem sentir-se apavoradas, solitárias ou culpadas, como se tivessem falhado de alguma forma ${ }^{(2)}$.

Somando-se aos sentimentos, às mudanças da rotina e a atenção se desviando para o recém-nascido, ocorre o declive acentuado dos hormônios estrógeno e progesterona, que pode levar a alguns transtornos emocionais; no período puerperal há maior chance de desenvolvimento de um transtorno humoral ${ }^{(2)}$.

Dessa maneira, é preciso experienciar a ligação e a sintonia que a puérpera tem com o filho para que possam ser tomadas decisões, mesmo que estas sejam simples, com base em seu próprio bom senso, intuição e sensibilidade. No entanto, a mulher que acabou de ter um filho é cercada de muitas opiniões que parecem corretas, mas que acabam por deixá-la com dificuldades de selecionar o que deve acatar, e impedindo-na de exercitar sua intuição de mãe. Neste momento, cabe à enfermagem realizar orientações sobre as dúvidas existentes de modo que a mesma adquira autoconfiança e autonomia nos cuidados ao bebêt(4-5).

O cuidado de enfermagem para a mulher que vivência o puerpério é imprescindível, e o profissional deve estar preparado para auxiliar a mulher na transição de gestante para puérpera, orientando-a e criando um espaço que permita a troca de experiências, a retirada de dúvidas no cuidado com o recém-nascido e com ela, mantendo-a saudável nesse novo papel que assume ${ }^{(6)}$.

No intuito de intervir nas relações vivenciadas pela mulher quanto a adaptação e a integração dos papeis que ela passa a assumir quando se torna mãe e a fim de contribuir para melhorar a sua qualidade de vida, faz-se necessário aos profissionais conhecer sobre as experiências da mulher durante este período. Neste sentido, este trabalho teve por objetivo desvelar os sentimentos da primípara frente ao cuidado com o recém-nascido.

\section{MÉTODO}

Trata-se de um estudo qualitativo com abordagem fenomenológica, a qual tem por objetivo interrogar a experiência vivida de modo único e pessoal e o significado que o sujeito lhe atribui, ou seja, procura não priorizar o objeto e/ou sujeito, mas centrar-se na relação sujeito-objeto-mundo. Assim, possibilita ao pesquisador o acesso à consciência humana, às essências, o que significa chegar à verdade, à realidade desprovida de estereótipos, estigmas, abandonando preconceitos e pressupostos em relação ao fenômeno interrogado ${ }^{(7)}$.

O estudo, realizado no período de maio a agosto de 2010, foi aprovado pelo Comitê de Ética em Pesquisa da UNIFAL sob o protocolo n. 074/2010. Em respeito à Resolução 196/96, que regulamenta a pesquisa envolvendo seres humanos, após a assinatura do Termo de Consentimento Livre e Esclarecido e esclarecimento sobre dúvidas e da publicação dos dados, os mesmos foram coletados pelas autoras. A abordagem inicial das puérperas ocorreu na maternidade da Casa de Caridade Nossa Senhora do Perpétuo Socorro em Alfenas, Minas Gerais, após autorização desta instituição as quais foram posteriormente entrevistadas.

A delimitação do número de sujeitos ficou definida a partir do momento em que foi percebido que os depoi- 
mentos desvelaram o fenômeno investigado, à medida que o pesquisador se familiariza com as descrições e observa a repetição e a convergência das indagações feitas ao sujeito da pesquisa, atingindo o ponto de saturação ${ }^{(7)}$. O encerramento da inclusão de novas mulheres foi decidido com base no conjunto dos dados coletados que evidenciaram tanto a riqueza, como as abrangências dos significados contidos nos depoimentos. Assim sendo, os depoimentos foram trabalhados e considerados suficientes para trazer à luz o fenômeno.

A coleta de dados, por meio de entrevista, foi realizada na residência da puépera após décimo dia do parto, em horário pré-agendado, gravadas mediante autorização das 11 puérperas primíparas que compuseram o grupo de estudo. A entrevista foi iniciada utilizando-se a questão: $O$ que é para você cuidar do seu recém-nascido?

Para análise das falas das puérperas, transcritas na íntegra, cada depoimento foi lido cuidadosamente, e foram selecionados e sublinhados trechos com os aspectos relativos ao objetivo do estudo. Os trechos sublinhados foram reescritos, agrupados conforme os aspectos que se relacionaram a um mesmo assunto, de forma a possibilitar sua separação e categorização. Cada grupamento recebeu o nome de uma categoria para representar a ideia central dos trechos ali contidos.

Os sentimentos e as experiências das puérperas foram compreendidos, por meio da análise dos três diferentes temas, identificados após a organização dos depoimentos, sendo eles: Sentimentos ao cuidar do recém-nascido; Cuidado físico com o recém-nascido e Sentimentos da mulher em relação ao companheiro frente ao cuidado com o recém-nascido.

\section{RESULTADOS}

\section{Sentimentos ao cuidar do recém-nascido}

As unidades de significado da categoria Sentimentos ao cuidar do recém-nascido desvelaram situações em que envolvem dificuldades e inseguranças que estão permeadas pelo temor das mães potencializado por se tratar do primeiro filho e pela falta de experiência. Fato explicado de duas maneiras pelas primigestas: pela concepção de que o recém-nascido é um ser frágil, principalmente enquanto cicatriza o umbigo, e pela insegurança que advém da falta de experiência do cuidado com o bebê.

Podemos ilustrar tais sentimentos nos depoimentos a seguir:
[...] teve uns dias que eu tava insegura e comecei a chorar também, aí eu não sei se é porque eu estava sozinha [...]. (D1)

[...] porque no começo eu tinha medo do umbiguinho, eu prefiro deixar eles pegarem um pezinho [...]. (D6)

[...] é uma coisa muito delicada que a gente tem que ter muita responsabilidade, muita paciência, pra ser mãe [...] a maior dificuldade foi dar banho e curar o umbigo, porque nossa se não fosse a minha mãe que me ajudou. (D7)

Sabemos que no decorrer do período gravídico-puerperal a mulher passa por diferentes mudanças, que interferem em seu mundo intrapsíquico e relacional. Altera-se significativamente a visão que ela tem de si mesma e de sua relação com o mundo. Nota-se sentimentos diversos e ambíguos, pois há momentos em que festejam a nova condição, e outros em que não se percebem adaptadas, como demonstra o depoimento a seguir:

[...] os sentimentos ficam muito divididos, porque o bebê ocupa muito tempo, e a gente não tem tempo prá mais nada! É dar de mamar e trocar fralda o dia inteiro, mas ele é tão bonzinho! (D10)

Os primeiros dias de convívio com o recém-nascido no domicílio são desafiadores para as primigestas, pois, o adaptar a nova situação de puérpera e cuidar de um novo ser representou sentimentos conflitantes de proteção a cria e de cuidados com o seu corpo. Se afastar do recém-nascido e compreender o comportamento do bebê, gerou ansiedade. A preocupação de cuidar adequadamente e acalmar a criança, nesses momentos, foi apontada pelas mães como uma dificuldade no exercício do cuidado materno, podemos inferir tais sentimentos ao período de adaptação materna.

[...] mas não adaptei a nova rotina ainda, eu vou ao banheiro correndo e minha mãe diz: não minha filha, pode deixar ela quietinha aí!. Mas eu não deixo, eu não consigo entendeu, deixar ela sozinha não [...]. (D3)

[...] estou me adaptando a toda essa mudança, eu passei muita dor, pensei que meus pontos tinham até inflamado, fui no hospital, mas agora tá tudo bem. (D10)

\section{O cuidado físico com o recém-nascido}

Este cuidado envolve o banho, a alimentação, a vacinação, o teste do pezinho e o curativo do coto 
umbilical, dentre outros cuidados. Observou-se que o curativo do coto umbilical e a amamentação foram os itens de maior preocupação entre as entrevistadas, as quais demonstraram insegurança, receio e medo.

Ah! Então, está sendo muito bom, porque eu nunca tive essa experiência. ai agora o jeito de dar banho, de curar o umbigo, eu até tinha muito medo, mas agora depois que eu tive orientação no hospital, eu até dei o banho nele aqui (residência) ejá perdi o medo. Eu que estou dando o banho direitinho, curando o umbigo [...]. (D5)

Além de todo esse estresse, eu tive muita fraqueza e quando eu ia amamentar minha filha eu passava muito mal começava e suar e, de repente desmaiava. Mas a vontade de amamentar falou mais alto e então melhorei minha alimentação, o médico me passou alguns suplementos de vitamina para poder amamentar ela e vejo que graças a Deus valeu a pena. Apesar de tudo, vale a pena e eu passaria por tudo de novo só para ter minha filha sempre comigo. (D3)

Os cuidados com o récem nascido foram gradativamente assumidos pelas mães, tanto o manejo com o coto umblical quanto o aleitamento materno. Diante do aleitamento materno as unidades de significado desvelaram satisfação e desejo durante a amamentação os quais se sobrepuseram aos pontos negativos de desconforto e medo.

\section{Sentimentos da mulher em relação ao companheiro frente ao cuidado com o recém-nascido}

Os depoimentos relatam a satisfação da puérpera em ter o esposo como facilitador do cuidado com o recém-nascido, o qual auxilia em tarefas simples como trocar fralda, dar banho e acalentar o que envolve sentimentos de paternidade.

[...] Meu marido ajuda muito, ajuda bastante. Acho que era ele que queria o filho mais do que eu, sabe? Então ele faz de tudo, banho ele não dá mais se precisar trocar ele troca, ele pega no colo e faz parar de chorar [...]. (D5)

[...] meu esposo me ajuda tanto, é até bom por o marido para trabalhar um pouquinho. O casamento ficou até melhor, porque a gente fica mais responsável e mais maduros [...]. (D10)

\section{DISCUSSÃO}

A gestação e o nascimento constituem para a mulher e para o homem fases de mudanças, com transformações e incertezas que acompanham a aquisição de novos papeis e responsabilidades antes inexistentes, incluindo-se as relacionadas com o novo integrante da família. Assim, a paternidade e a maternidade são permeadas por conflitos determinados pela situação nova que o casal vivencia, a qual despertam diferentes sentimentos como a alegria, a tristeza, a satisfação e a insatisfação ${ }^{(8)}$.

Os trabalhos que levam em consideração a figura paterna detêm sua valorização na rede de apoio emocional que o mesmo oferece à mãe durante a gravidez, no cuidado pós-parto e nas atividades domésticas ${ }^{(6,9)}$. Essas tarefas dependem do envolvimento afetivo do pai com o novo papel assumido e o que ele pretende desenvolver; em relação à atitude do companheiro as puérperas relataram satisfação. Os relatos desvelaram maior solidez no relacionamento conjugal, visto que, a aproximação do casal foi notória, apontando assim, uma satisfação em relação às mudanças ocorridas, especialmente pelo fato de os companheiros terem passado a dividir mais as tarefas dentro de casa ${ }^{(9)}$. Inferimos assim, uma mudança de gênero diante do cuidado, o qual, em décadas anteriores, era realizado apenas pelas mulheres e hoje se percebe o auxílio do pai frente essa tarefa, mostrando uma mudança de paradigma cultural.

O pós-parto mostra-se um período de vulnerabilidade emocional e física para as mulheres que podem estar psicologicamente sobrecarregadas com a responsabilidade de desenvolver um novo papel, o de ser mãe ${ }^{(10)}$. Nas puérperas desta pesquisa observamos esse sentimento de vulnerabilidade, principalmente, por se tratar do primeiro filho. A nova realidade exigiu a adaptação ao novo ser; a primípara passou a conciliar os cuidados com o recém-nascido, a rotina familiar, social e conjugal, bem como, as modificações emocionais e físicas enfrentadas.

O cuidar do filho gerou sentimentos conflituosos nas mulheres, mesmo sendo o cuidado da constituição do ser humano, e é esse sentimento que dá sentido à vida e permite executar o cuidado com si próprio e com o outro ${ }^{(11)}$. Neste trabalho o sentimento de cuidar de um ser ingênuo e sem defesas próprias, ou seja, o primeiro filho é aflorado em todas as primíparas. Desvelamos isso pelas falas das mesmas quando enfatizam a satisfação do cuidar mesmo em situações de dor, insegurança e medo. 
O recém-nascido é um ser frágil e que requer uma série de cuidados como banho, alimentação, adaptação ao novo ambiente, curativo do coto umbilical, o que leva a mulher a desenvolver novos papeis, destacamos que mesmo se sentindo insegura a mesma realizou os cuidados ao recémnascido necessários para a sobrevivência do mesmo.

As primíparas demonstraram sentimentos de insegurança em relação ao manuseio e à queda do coto umbilical, reforçando o fato de que, para as mulheres, o coto umbilical é envolto em mistério e desconhecimento. É interessante observar que as entrevistadas utilizavam procedimentos assépticos para cuidar do coto umbilical prevenindo infecção, promovendo a desidratação, a mumificação e queda. Não houve relatos de crendices como enfaixar o coto, colocar moeda e utilizar/passar diferentes ingredientes como banha de galinha, azeite, arruda e folha de fumo, ao contrário de outros trabalhos que referem o desconhecimento da mãe frente ao curativo do coto umbilical ${ }^{(12-13)}$ Isto nos leva a inferir que essas mulheres estão instruídas em relação ao cuidado com o coto umbilical, mesmo diante da inexperiência e insegurança.

Nos relatos dos depoimentos observamos que, mesmo diante das dificuldades enfrentadas pelas entrevistadas, o fortalecimento do vínculo com o recémnascido e a superação de muitas dessas dificuldades e medos, torna a puérpera primípara cada vez mais confiante, percebendo-se capaz para prestar os cuidados ao recém-nascido.

\section{CONSIDERAÇÕES FINAIS}

Ao longo da pesquisa ficou evidenciado que as primíparas denotam uma gama de sentimentos positivos ao serem questionadas sobre a experiência de cuidar do seu filho. Percebemos que o bebê nos braços da mãe é o responsável direto pela alegria que sentem e que apesar do medo e insegurança, elas se sentem capacitadas para cuidar, pois os sentimentos positivos sobressaem sobre os negativos.

Os sentimentos que as mães externaram em relação às transformações físicas e emocionais refletem sua percepção de que já não são as mesmas, de que agora seu corpo e sua função no mundo mudaram. Pode-se entender este momento como um dos principais da maternidade sem esquecer que antes disto, obviamente, ela nasceu mulher, foi filha e brincou de ser mãe o que foi contribuindo para a constituição da maternidade, que também é fortemente influenciada por determinantes biológicos, psíquicos e culturais. Mas agora ela é a mãe, atenta para o seu mundo interno e se reorganiza, uma vez que já não mais se vê como única, e sim, com um bebê.

Diante de tais sentimentos inferimos a importância da assistência de enfermagem à mulher no ciclo gravídico-puerperal, seja no pré-natal, na unidade de internação, no Alojamento Conjunto ou em unidades da rede básica, pois representa uma fase que requer discussão e ações efetivas para alcançar a humanização dos cuidados como um passo para a integralidade no atendimento à mulher. Como profissionais, vemos a necessidade de uma intervenção multidisciplinar com objetivo de orientar às mães sobre o cuidado com o bebê utilizando como estratégia a adesão aos familiares.

O puerpério é um momento de extrema importância na vida da mulher, é um ritual de passagem que deve ser vivido de forma positiva e a enfermagem está em uma posição privilegiada, no que se refere ao atendimento à mulher que vivencia esse período, pois incorpora a arte do cuidar de forma humanizada respeitando os direitos das mulheres a uma maternidade segura e prazerosa.

\section{REFERÊNCIAS}

1. Smeltzer SC, Bare BG. Brunner \& Suddarth - Tratado de enfermagem médico cirúrgica. $12^{\mathrm{a}}$ ed. Rio de Janeiro: Guanabara-Koogan; 2009.

2. Ricci SS. Enfermagem materno e neonatal e saúde da mulher. Rio de Janeiro: Guanabara Koogan; 2008.

3. Merighi MAB, Gonçalves R, Rodrigues, IG. Vivenciando o período puerperal: uma abordagem compreensiva da Fenomenologia Social. Rev. bras. enferm. 2006;59(6):775-9.

4. Oliveira JFB, Quirino GS, Rodrigues DP. Percepção das puérpera quanto aos cuidados prestados pela equipe de saúde no puerpério. Rev. Rene. 2012;13(1):74-84.

5. Silva LA, Nakano AMS, Gomes FA, Stefanello J. Significados atribuídos por puérperas adolescentes à maternidade: autocuidado e cuidado com o bebê. Texto Contexto enferm. 2009;18(1):48-56.

6. Alves AM, Gonçalves CSF, Martins MA, Silva ST, Auwerter TC, Zagonel IPS. A enfermagem e puérperas primigestas: desvendando o processo de transição ao papel materno. Cogitare enferm. 2007;12(4):416-27.

7. Merighi MAB, Praça NS. Abordagens teórico metodológicas qualitativas: a vivência da mulher no período reprodutivo. $1^{\mathrm{a}}$ ed. Rio de Janeiro: Guanabara Koogan, 2003. 
8. Sampaio MA, Falbo AR, Camarotti MC, Vasconcelos MGL. Resultados preliminares de um estudo qualitativo sobre a interação entre mãe e criança desnutrida grave, no contexto da hospitalização. Rev. Bras. Saúde Mater. Infant. 2007;7(Supp 11):S29-36.

9. Oliveira EMF, Brito RS. Ações de cuidado desempenhadas pelo pai no puerpério. Esc. Anna Nery rev. enferm. 2009; 13(3): 595-601.

10. Cabral FB, Oliveira DLLC. Vulnerabilidade de puérperas na visão de Equipes de Saúde da Família: ênfase em aspectos geracionais e adolescência. Rev. Esc. Enferm. USP. 2010;44(2):368-75.

11. Boff, L. Saber cuidar: ética do humano-compaixão pela terra. 16ª ed. Petrópolis: Vozes; 2009.

12. Andrade LCO, Santos MS, Aires JS, Joventino ES, Dodt RCM, Ximenes LB. Conhecimento de puérperas internadas em um alojamento conjunto acerca da higiene do neonato. Cogitare enferm. 2012;17(1):99-105.

13. Souza MHN, Gomes TNC, Paz EPA, Trindade CST, Veras RCC. Estratégia acolhimento mãe-bebê: aspectos relacionados à clientela atendida em uma unidade básica de saúde do Município do Rio de Janeiro. Esc. Anna Nery. 2011;15(4):671-7. 